\title{
IMPACT OF HYDROXYPROPYL METHYLCELLULOSE (HPMC) TYPE AND CONCENTRATION ON THE SWELLING AND RELEASE PROPERTIES OF PROPRANOLOL HYDROCHLORIDE MATRIX TABLETS USNING A SIMPLEX CENTROID DESIGN
}

\author{
PAKORN KRAISIT* \\ Division of Pharmaceutical Sciences, Faculty of Pharmacy, Thammasat University, Pathumthani, 12120 Thailand
}

Email: pakorn54@tu.ac.th

Received: 03 Dec 2018, Revised and Accepted: 30 Jan 2019

\begin{abstract}
Objective: To prepare hydroxypropyl methylcellulose (HPMC) matrix tablets of propranolol hydrochloride (PNL) using a simplex centroid design.

Methods: HPMC matrix tablets with different amounts and types of HPMC were prepared by direct compression. A simplex centroid design was used to evaluate tablet weight $\left(\mathrm{Y}_{1}\right)$, thickness $\left(\mathrm{Y}_{2}\right)$, hardness $\left(\mathrm{Y}_{3}\right)$, axial swelling time at $0.5-12 \mathrm{~h}\left(\mathrm{Y}_{4}-\mathrm{Y}_{9}\right)$, radial swelling time at $0.5-12 \mathrm{~h}\left(\mathrm{Y}_{10}-\mathrm{Y}_{15}\right)$, and $\%$ released at $1-12 \mathrm{~h}\left(\mathrm{Y}_{16}-\mathrm{Y}_{19}\right)$.

Results: The tablet weight, thickness, and hardness were 397.6-400.4 mg, 3.967-4.029 mm, and 106.9-139.0 N, respectively. The \% swelling (axial) and \% swelling (radial) at $0.5-12 \mathrm{~h}$ were- 8.715 to 59.889 and-1.887 to 49.287 , respectively. The negative \% swelling could be attributed to erosion of the tablets. The in vitro release of PNL from the tablets in buffer solution pH $1.2(1 \mathrm{~h})$ and pH $7.5(3-12 \mathrm{~h})$ was 21.12-76.22\%. Tables with a high proportion of K100M HPMC had high PNL release, and the mechanism of PNL release was diffusion-and erosion-controlled.
\end{abstract}

Conclusion: The simplex centroid design is potentially advantageous for formulating PNL-HPMC matrix tablets.

Keywords: Hydroxypropyl methylcellulose (HPMC), Matrix tablets, Simplex centroid design, Design of experiment, Propranolol hydrochloride, Swelling, Release mechanism

(C) 2019 The Authors. Published by Innovare Academic Sciences Pvt Ltd. This is an open access article under the CC BY license (http://creativecommons.org/licenses/by/4.0/) DOI: http://dx.doi.org/10.22159/ijap.2019v11i2.31127

\section{INTRODUCTION}

The tablet dosage form is an extensively used oral administration route, as it is easy to handle, easy to manufacture, economical, and has good stability and painless administration when compared with other pharmaceutical routes [1]. However, the drug release rate cannot be controlled with conventional tablets, leading to the risk of toxicity due to dose dumping, and some drugs require several doses daily to sustain therapeutic levels in the bloodstream [2]. This issue is resolved with oral controlled-release dosage forms, and one interesting selection in this system is the hydrophilic polymer matrix. This matrix is very popular for prolonging drug release because it is easy and economical to manufacture, has high reproducibility, good stability, increases patient compliance, and decreases incidences of drug toxicity from dose dumping [3-5]. The drug release mechanisms of the hydrophilic polymer matrix generally involve three steps: dissolution, diffusion through swelling polymers, and erosion [6-8]. Hence, the hydrated gel layer of the matrix is formed by hydrophilic polymer swelling after interaction with water. This layer is a crucial influencing factor of the control of drug release from the matrix [3, 7]. Moreover, hydrophilic polymer type and concentration also affect gel layer formation and the drug release rate of matrix tablets, and an interesting choice of hydrophilic polymer is hydroxypropyl methylcellulose (HPMC).

HPMC is an extensive hydrophilic polymer used in many pharmaceutical dosage forms, including as a hydrophilic matrix form with prolonged drug release [4, 9]. HPMC has many advantages such as ease of use and compression, high levels of drug loading, stability at a wide range of $\mathrm{pH}$, and rapid swelling [4, 9-11]. There are several grades of HPMC based on the molecular weight, methoxy group content percentage $\left(-\mathrm{OCH}_{3}\right)$, and hydroxypropoxy group percentage $\left(-\mathrm{OCH}_{2} \mathrm{CH}(\mathrm{OH}) \mathrm{CH}_{3}\right)$ of the molecular structure, resulting in different HPMC viscosities and physical properties [6, 8]. Bose et al. used three ratios of various HPMC grades to formulate matrix tablets, and found that altering the ratios of the HPMC grades could control the drug release rate from the matrix [6]. Additionally, many researchers use HPMC for preparing extended-release tablets of various model drugs such as itopride, hydrocortisone, theophylline, propranolol, and isoniazid $[2,5,6,12]$.

Propranolol hydrochloride (PNL), a $\beta$-adrenergic blocking agent, is commonly used for treating hypertension, angina pectoris, and cardiac arrhythmia $[2,4,10]$. Normally, the conventional tablet form PNL has to be taken three or four daily to maintain drug levels in the bloodstream within the therapeutic range, as its half-life in the circulation is short $[10,13]$. After oral administration, PNL can be absorbed entirely through the gastrointestinal tract membrane, but only $25-30 \%$ bioavailability is achieved due to the hepatic first-pass effect $[2,10]$. Thus, hydrophilic polymer matrix tablets may be a suitable dosage form for reducing the number of doses taken in one day and helps improve patient compliance.

The traditional trial-and-error method of formulating matrix tablets has many disadvantages such as being time-consuming, laborious, expensive, and unpredictable [2,14]. Therefore, design of experiment (DOE) is used to resolve the problems encountered with the traditional method and is useful for manipulating complex formulations or formulations that involve many variables $[14,15]$. Based on these rationales, DOE is an interesting technique and has been widely used for many pharmaceutical dosage forms $[1,2,6,14,16]$.

The present study used the simplex centroid design DOE to evaluate the effect of HPMC concentration and type on the weight, thickness, hardness, \% swelling, and \% release of PNL from HPMC matrix tablets. Therefore, the objective was to prepare HPMC matrix tablets of PNL using a simplex centroid design approach.

\section{MATERIALS AND METHODS}

\section{Materials}

K4M (H-K4M), K15M (H-K15M), and K100M HPMC (H-K100M) (Methocel ${ }^{\circledR}$ ) were manufactured by Dow Chemical Company (Midland, MI, USA) and kindly supported by Rama Production Co., Ltd. (Bangkok, Thailand). Propranolol $\mathrm{HCl}$ was purchased from PC Drug Co. Ltd. (Bangkok, Thailand). All other chemicals used were of analytical grade and were used as received. 


\section{Preparation of HPMC matrix tablets}

Direct compression was used to prepare HPMC matrix tablets containing different amounts and types of HPMC (table 1). First, accurate amounts of PNL, HPMC, microcrystalline cellulose and dihydrate dibasic calcium phosphate were mixed using mortar and pestle until the compounds were uniform. The other ingredients were added and manually blended in a polybag for $5 \mathrm{~min}$. The mixture was compressed using a hydraulic press (Model 15011, Specac, Fort Washington, PA, USA) with a 9.5-mm diameter flat-faced punch at a compression force of 1 ton and a dwell time of 10 seconds. The tablets were stored in a vacuum desiccator before testing.

Table 1: The simplex centroid design of HPMC matrix tablets

\begin{tabular}{|c|c|c|c|}
\hline \multirow[t]{2}{*}{ Formulation } & \multicolumn{3}{|c|}{ An actual value of independent factors } \\
\hline & H-K4M (mg), ( $\left.\mathrm{X}_{1}\right)$ & H-K15M (mg), ( $\left.\mathrm{X}_{2}\right)$ & H-K100M (mg), $\left(X_{3}\right)$ \\
\hline $\mathrm{T} 1$ & 0 & 0 & 60 \\
\hline $\mathrm{T} 2$ & 0 & 30 & 30 \\
\hline T3 & 0 & 60 & 0 \\
\hline $\mathrm{T} 4$ & 10 & 10 & 40 \\
\hline T5 & 10 & 40 & 10 \\
\hline T6 & 20 & 20 & 20 \\
\hline T7 & 30 & 0 & 30 \\
\hline $\mathrm{T} 8$ & 30 & 30 & 0 \\
\hline T9 & 40 & 10 & 10 \\
\hline $\mathrm{T} 10$ & 60 & 0 & 0 \\
\hline $\mathrm{T} 11$ & 60 & 0 & 0 \\
\hline
\end{tabular}

\section{Simplex centroid design and statistical analysis}

A simplex centroid design was used to evaluate the effect of HPMC concentration and type on the tablet weight, thickness, hardness, $\%$ swelling, and \% release. The tablet formulation components are shown in table 1 . The three main ingredients, namely H-K4M $\left(\mathrm{X}_{1}\right), \mathrm{H}-$ $\mathrm{K} 15 \mathrm{M}\left(\mathrm{X}_{2}\right)$, and $\mathrm{H}-\mathrm{K} 100 \mathrm{M}\left(\mathrm{X}_{3}\right)$, were identified as casual factors. The upper and lower limits of each component were set as follows:

$$
\begin{gathered}
0 \leq X_{1} \leq 100(\%) \ldots \ldots \ldots . . .(1) \\
0 \leq X_{2} \leq 100(\%) \ldots \ldots . .(2) \\
0 \leq X_{3} \leq 100(\%) \ldots \ldots . .(3) \\
X_{1}+X_{2}+X_{3}=100(\%) \ldots \ldots . .(4) \\
X_{1}+X_{2}+X_{3}=60.0(\mathrm{mg}) \ldots \ldots .(5)
\end{gathered}
$$

The three main ingredients of the tablet formulations were changed concurrently and the whole amount was adjusted to $100 \%$ (60 mg).

The tablet characteristics, i.e., weight $\left(\mathrm{Y}_{1}\right)$, thickness $\left(\mathrm{Y}_{2}\right)$, hardness $\left(\mathrm{Y}_{3}\right)$, axial swelling time at $0.5-12 \mathrm{~h}\left(\mathrm{Y}_{4}-\mathrm{Y}_{9}\right)$, radial swelling time at $0.5-12 \mathrm{~h}\left(\mathrm{Y}_{10}-\mathrm{Y}_{15}\right)$, and \% released at 1-12 h $\left(\mathrm{Y}_{16}-\mathrm{Y}_{19}\right)$ were defined as dependent variables. Design-Expert ${ }^{\circledR}$ software (version 9; StatEase, Inc., Minneapolis, MN, USA) was used to estimate the responses of all model tablets. A total of 11 random runs, three levels, and three factors were planned by the software, and the setting variables were used as required. Analysis of variance (ANOVA) was used for the statistical analysis.

\section{Characterization of HPMC matrix tablets}

Three physical properties (weight, thickness, hardness) of the tablets were examined at room temperature $\left(\mathrm{ca} .25^{\circ} \mathrm{C}\right)$. Each tablet was weighed using a weighing machine (AC 210 S, Sartorius, Göttingen, Germany) for computing the weight variation $(\mathrm{n}=20)$. The thickness and hardness of 10 tablets were inspected simultaneously using thickness and hardness tester (TBH 225 TD, ERWEKA, Heusenstamm, Germany).

\section{Swelling behavior of HPMC matrix tablets}

The swelling and erosion behavior of the tablets was determined by optical observation, where tablets were submerged in dissolution media; the method was modified from a previously reported method in Nunthanid et al. [17]. This method has an advantage over the gravimetric technique because there is no interruption from error of wiping excess medium from the samples during weighing. In addition, all data from this method are real-time and obtained in situ [17]. For the radial swelling test, each tablet was fixed to a petri dish with double-sided adhesive tape, and buffer solution $\mathrm{pH}$ 1.2, containing $2 \mathrm{~g} \mathrm{NaCl}$ and $7.0 \mathrm{ml} \mathrm{HCl}$ per liter distilled water adjusted to $\mathrm{pH} 1.2$ with $\mathrm{NaOH}$ or $\mathrm{HCl}$ ) was added at $0.5 \mathrm{~h}$ and $1 \mathrm{~h}$. After $1 \mathrm{~h}$, the test medium was carefully removed and changed to buffer solution ( $\mathrm{pH} 7.5$, containing $6.8 \mathrm{~g} \mathrm{KH}_{2} \mathrm{PO}_{4}$ and $1.6 \mathrm{~g} \mathrm{NaOH}$ per liter distilled water adjusted to $\mathrm{pH} 7.5$ with $\mathrm{NaOH}$ or $\mathrm{HCl}$ ) at 2,3,6, and 12 h. For the axial swelling test, open-ended tubes with the same diameter as the tablets were modified to observe the axial swelling. The medium and predetermined times of axial swelling were as described in the radial swelling test. Each swelling test was performed in quadruplicate, and the $\%$ swelling was calculated using the following equations:

$$
\begin{aligned}
& \%_{\text {S Swelling (radial) }}=\frac{\mathrm{A}_{\mathrm{t}}-\mathrm{Ao}}{\mathrm{A}_{\mathrm{o}}} \times 100 \ldots \ldots . .(6) \\
& \% \text { Swelling (axial) }=\frac{\mathrm{H}_{\mathrm{t}}-\mathrm{H}_{\mathrm{o}}}{\mathrm{H}_{\mathrm{o}}} \times 100 \ldots \ldots .(7)
\end{aligned}
$$

Where $A_{o}$ and $H_{o}$ are the upper surface area ( $\pi(D o / 2), D_{o}$ is tablet diameter) and thickness of the initial dry tablet, respectively. $A_{t}$ and $\mathrm{H}_{\mathrm{t}}$ are the upper surface area and thickness of the radial and axial swelling of the tablet at time t, respectively.

\section{In vitro release of HPMC matrix tablets}

The release of PNL from the tablets was investigated using the United States Pharmacopeia (USP) Dissolution Test 2 of PNL extended-release capsules (basket method, $50 \mathrm{rpm}$ ). Buffer solution ( $900 \mathrm{ml}, \mathrm{pH} 1.2$ ) in each vessel was used as the dissolution medium in the first hour and maintained at $37^{\circ} \mathrm{C}$. The release medium $(5 \mathrm{ml})$ was removed, and then the entire medium was removed. Next, the same amount of buffer solution ( $\mathrm{pH} 7.5$ ) as the previous medium was added, $5 \mathrm{ml}$ release medium was removed at 3,6 , and $12 \mathrm{~h}$, and an equal volume of fresh medium was replaced at each time. The amount of PNL was analyzed using spectrophotometry at $320 \mathrm{~nm}$ (Agilent, model 1100 series, Santa Clara, CA, USA). Six tablets per formulation were used and the percentage PNL released was calculated.

\section{Release data analysis}

The drug release kinetics of the tablets was matched with zeroorder, first-order, Higuchi, and Korsmeyer-Peppas equations (Eqs.8-11, respectively), as follows:

$$
\begin{gathered}
\mathrm{Q}=\mathrm{Q}_{0}+\mathrm{K}_{0} \mathrm{t} \ldots \ldots \ldots . .(8) \\
\log \mathrm{Q}=\log \mathrm{Q}_{0}-\mathrm{K}_{1} \mathrm{t} / 2.303 \ldots \ldots \ldots(9) \\
\mathrm{Q}=\mathrm{K}_{\mathrm{h}} \mathrm{t}^{1 / 2} \ldots \ldots \ldots . .(10) \\
\mathrm{M}_{\mathrm{t}} / \mathrm{M}_{\alpha}=\mathrm{K}^{\mathrm{n}} \ldots \ldots \ldots . .(11)
\end{gathered}
$$

where $Q$ is the cumulative amount of drug release at time $(t)$, $M_{t} / M_{\alpha}$ the fractional drug release at time $(t), t$ the time in hours, $Q_{0}$ the 
initial amount of drug in the solution, $\mathrm{K}_{0}$ the zero-order release constant, $\mathrm{K}_{1}$ the first-order release constant, $\mathrm{K}_{\mathrm{h}}$ the Higuchi constant, $\mathrm{K}$ the Korsmeyer-Peppas constant, and $\mathrm{n}$ the release exponent indicative of the drug release mechanism. The value of $\mathrm{n}$ was used to predict the drug release mechanism, and a maximum $\mathrm{R}^{2}$ of each equation was used to select the appropriate mathematical release model.

\section{RESULTS AND DISCUSSION}

\section{Characterization of HPMC matrix tablets}

Direct compression was used to prepare HPMC matrix tablets with different types and amounts of HPMC. Physical factors such as weight, thickness, and hardness affect the swelling properties and release of drugs from tablets. Consequently, these factors should be considered when preparing tablets. Fig. 1 shows the contour plot of the effect of the amount and type of HPMC on the physical properties of the tablets. The tablets weighed 397.6-400.4 mg and displayed only green areas in the contour plot (fig. 1A). From the result, it can be assumed that the concentrations of the various HPMC types did not significantly influence the tablet weight. The small variation in tablet weights may have been due to the use of a manual hydraulic press for weighing and compressing each tablet individually. The tablet is shown in fig. 1B and was 3.967-4.029 mm thick. The highest thickness could be seen only for tablets containing H-K15M (red color in the contour plot), but was not significant $(p>0.05)$. The hardness of the tablets ranged 106.9-139.0 N (fig. 1C). The high hardness value could be observed only in tablets with large proportions of $\mathrm{H}-\mathrm{K} 4 \mathrm{M}$ and $\mathrm{H}-\mathrm{K} 100 \mathrm{M}$. This could be explained by particle size, in that the tablet hardness decreased as the particle size of the compound increased [7]. A previous report demonstrated the particle size and size distribution of HPMC K-series and suggested that H-K100M had considerably smaller particle size than other-grade HPMC, and involved slightly narrower size distribution [18]. However, the hardness contour plot showed a small blue area at the corner denoting $\mathrm{H}-\mathrm{K} 100 \mathrm{M}$, referring to low hardness when the tablet formulation contained only H-K100M. Hence, the high hardness value may have been due to particle-particle interactions of suitable ratios of H-K4M and H-K100M [18].

The corresponding residual plot was used to check the reliability of the response variables. They are displayed in fig. $1 \mathrm{D}, 1 \mathrm{E}$, and $1 \mathrm{~F}$, which were plotted between the run number and the internally studentized residuals of $Y_{1}, Y_{2}$, and $Y_{3}$, respectively. In the fully randomized run, the vertical expansion of the internally studentized residuals was in line from bottom to top, indicating that all data points lay within the limits of a $95 \%$ confidence interval.
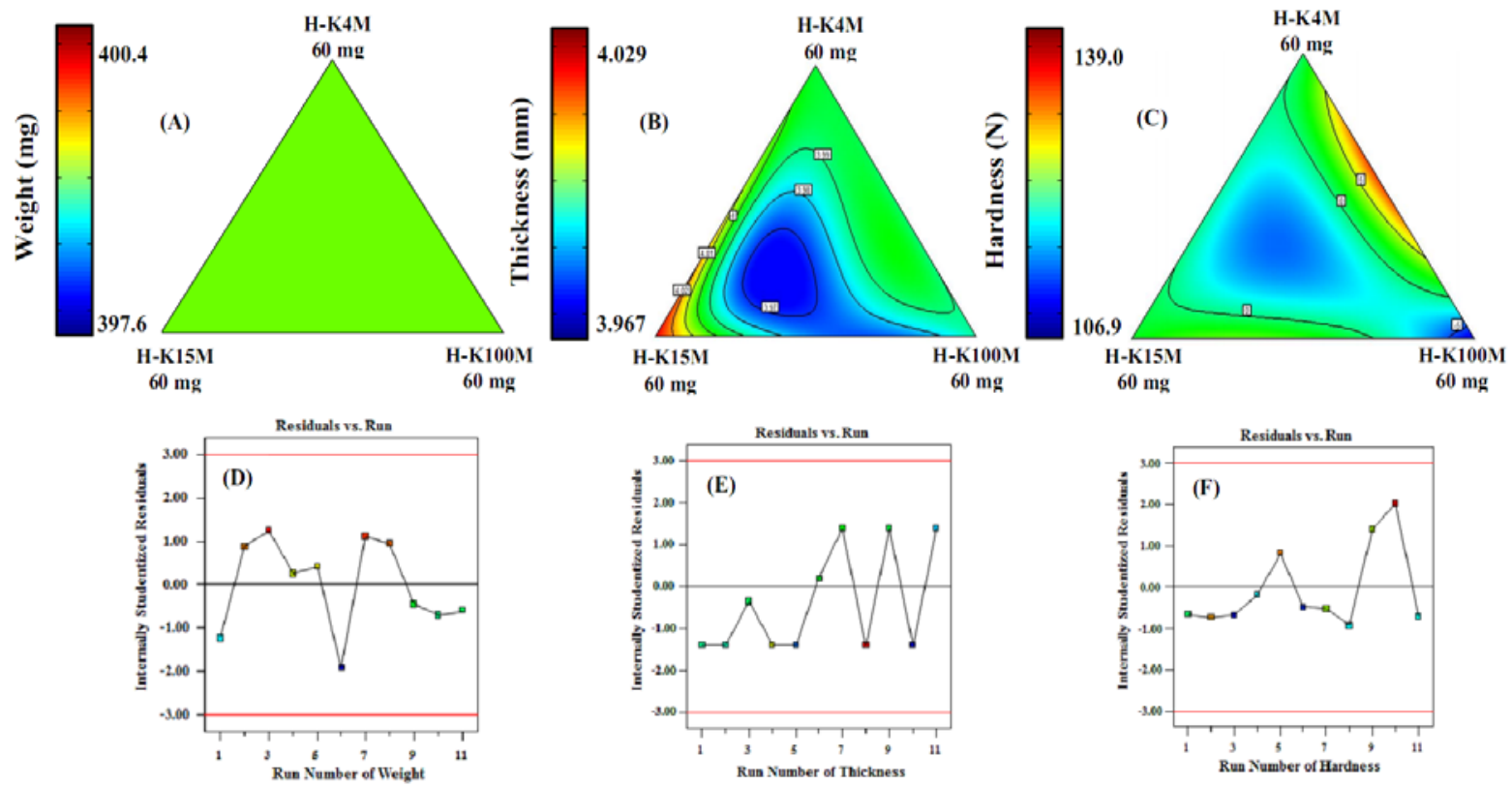

Fig. 1: Contour plots of HPMC matrix tablets for weight $\left(A, Y_{1}\right)$, thickness $\left(B, Y_{2}\right)$, hardness $\left(C, Y_{3}\right)$ and the corresponding residual plot between run number and internally studentized residuals for weight $\left(D, Y_{1}\right)$, thickness $\left(E, Y_{2}\right)$ and hardness $\left(F, Y_{3}\right)$

\section{Swelling behavior of HPMC matrix tablets}

Many researchers have reported the swelling properties of matrix tablets because they play a crucial role in drug release from the tablets $[7,17,19]$. The polymer-polymer and polymer-solvent interactions are major controlling factors of swelling and erosion [20]. When the media comes into contact with the tablets and water penetrates the tablets, consequently causing hydration, swelling, gel formation, and erosion may occur in parallel at the interface of the tablets. The swelling medium in the present study was the progressive $\mathrm{pH}$ medium. It comprised buffer solution ( $\mathrm{pH} 1.2)$ in the first $1 \mathrm{~h}$, and was subsequently changed to a buffer solution ( $\mathrm{pH} 7.5$ ) and maintained for the following $12 \mathrm{~h}$. The axial swelling illustrations and contour plot of \% swelling (axial) are shown in fig. 2 and fig. 3, respectively. The \% swelling (axial) at $0.5-12 \mathrm{~h}$ was-8.715 to 59.889 , and the negative \% swelling (axial) could be attributed to erosion of the tablets. The erosion in the first time period $0.5 \mathrm{~h}$ and $1 \mathrm{~h}$ ) was highest in tablets with high amounts of H-K100M (fig. 3A and $3 \mathrm{~B}$ ). The result correlated with the axial swelling fig. for the T1 and T4 formulations, in that there was more eroded powder around the tablets compared to the other formulations (fig. 2). Conversely, tablets with high amounts of H-K100M had more axial swelling than tablets of the other formulations at 6 and $12 \mathrm{~h}$. These appearances may be described in that in the first time period of axial swelling, the erosion rate of tablets with high amounts of high-molecular weight HPMC (H-K100M) was higher than the rate of swelling [20], but at a later time period, tablets with the highest-molecular weight HPMC had greater swelling rates than erosion rates [7]. Additionally, another report indicated that the higher-molecular weight HPMC type-K leads to increased contact angle between the HPMC surface and distilled water, exhibiting more hydrophobicity [21]. Hence, in equal concentrations, H-K100M was more hydrophobic than H-K4M and $\mathrm{H}-\mathrm{K} 15 \mathrm{M}$, reducing the amount of water penetrating the tablets and decreasing swelling [9]. The axial swelling during the final time period could be explained by the polymer chain entanglement [5, 21], which involves the viscosity of the polymer. At the same amount, H-K100M has higher viscosity than other HPMC K-types, constructing larger structural chain entanglement than low-viscosity HPMC $[5,21]$. Thus, it is difficult for high-molecular weight HPMC to dissolve due to the high energy needed to remove them fromthe 
tablets [5]. Then, following hydration in the last time period, tablets with H-K100M had more swelling than that with other HPMC types.

Only the green area in the contour plot in fig. 3D suggested no significant difference in the effect of HPMC amount and molecular weight on axial swelling at hour 3 . Axial swelling at hour 6-12 had different contour plot patterns from the early period, in that high amounts of low-molecular weight HPMC resulted in less swelling than higher amounts of high-molecular weight HPMC. This result correlates with another article reporting higher swelling of highmolecular weight polymers used for preparing matrix tablets than low-molecular weight polymers [7].

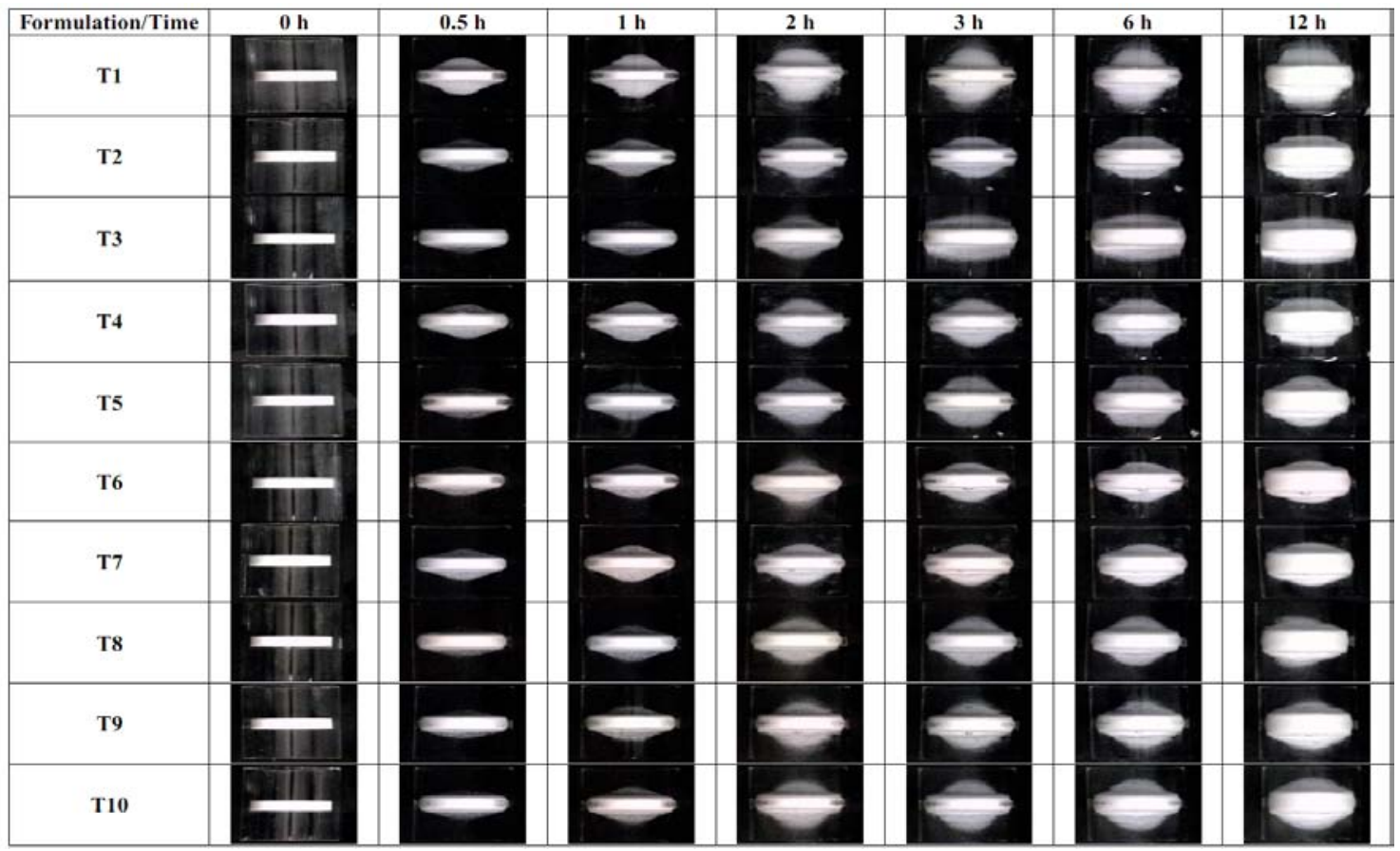

Fig. 2: Axial swelling behavior of HPMC matrix tablets at various times $\left(\mathrm{Y}_{4}-\mathrm{Y}_{9}\right)$
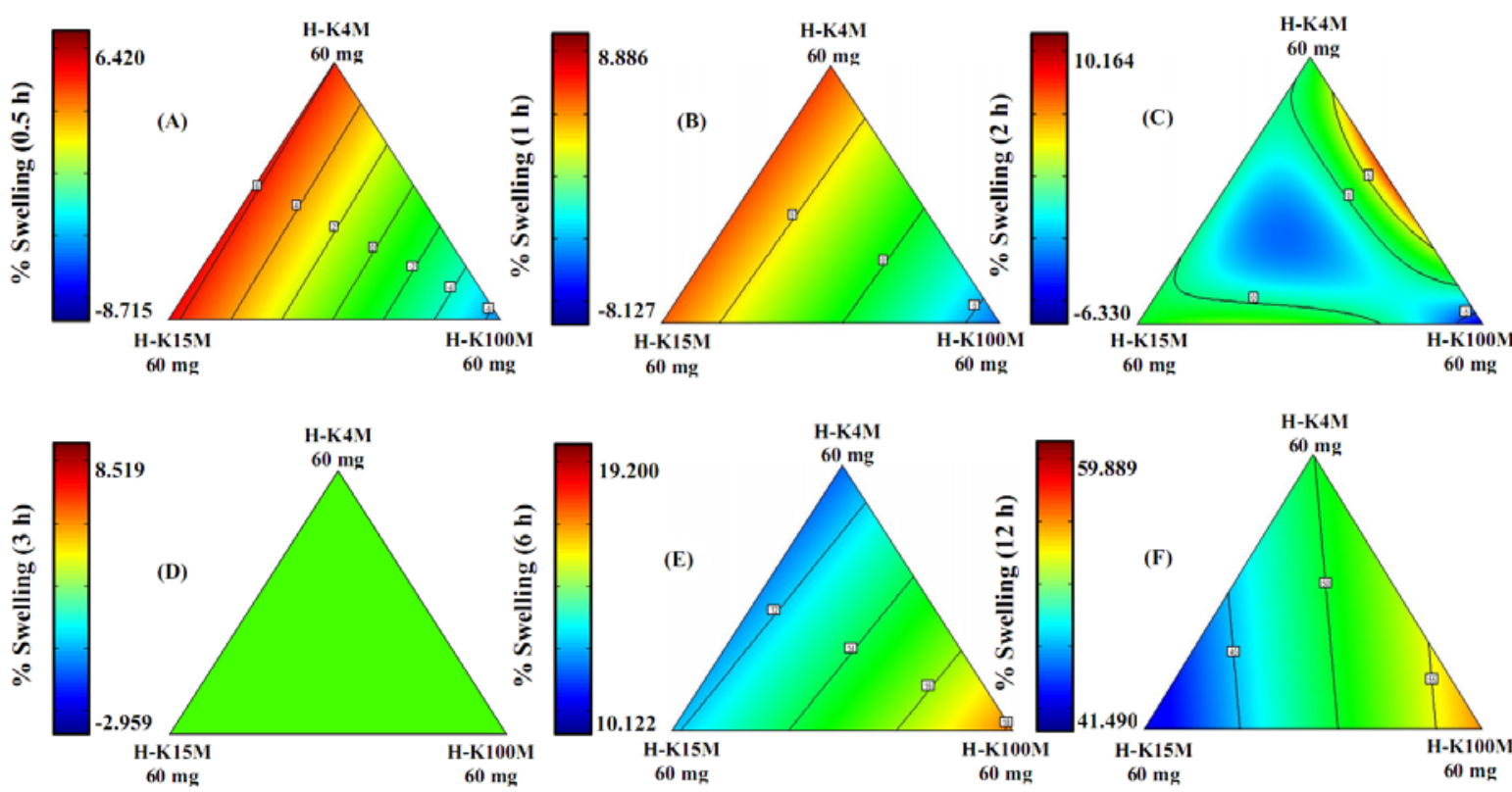

Fig. 3: Contour plots of HPMC matrix tablets for (\%) axial swelling at $0.5 \mathrm{~h}\left(\mathrm{~A}, \mathrm{Y}_{4}\right), 1 \mathrm{~h}\left(\mathrm{~B}, \mathrm{Y}_{5}\right), 2 \mathrm{~h}\left(\mathrm{C}, \mathrm{Y}_{6}\right), 3 \mathrm{~h}\left(\mathrm{D}, \mathrm{Y}_{7}\right), 6 \mathrm{~h}\left(\mathrm{E}, \mathrm{Y}_{8}\right)$ and $12 \mathrm{~h}\left(\mathrm{~F}, \mathrm{Y}_{9}\right)$

The radial swelling fig. and contour plot of \% swelling (radial) are shown in fig. 4 and fig. 5 , respectively. The \% swelling (radial) at $0.5-12$ $\mathrm{h}$ was- 1.887 to 49.287 , and the final value of radial swelling was lower than that of axial swelling. The radial swelling of the tablets containing different concentrations of HPMC at $0.5 \mathrm{~h}$ and $1 \mathrm{~h}$ were quite similar, and there was little erosion. However, tablet erosion was observed at hour 12 of radial swelling in the tablets with high amounts of H-K4M, i.e., the T9 and T10 formulations (fig. 4). This supports the reason above explaining why low-molecular weight HPMC swells less than high-molecular weight HPMC; conversely, it had a higher erosion rate than the high-molecular weight HPMC. At hour 2 of radial swelling, the obvious red area of the contour plot in 
fig. 5C shows the high swelling of the tablets containing high H-K4M and $\mathrm{H}-\mathrm{K} 100 \mathrm{M}$ ratios. At these concentrations, the swelling could not be sustained until the end of the experiment at hour 12. At hour 12, high swelling could be observed in the tablets with high H-K4M and $\mathrm{H}-\mathrm{K} 15 \mathrm{M}$ ratios; conversely, tablets with high $\mathrm{H}-\mathrm{K} 4 \mathrm{M}$ and $\mathrm{H}-\mathrm{K} 100 \mathrm{M}$ ratios became erodedat this point, as described earlier. Therefore, the different equilibrium swelling time of the tablets depends on the HPMC ratios and molecular weights.
The reliability of the response variable was ensured by operating with the corresponding residual plot. Fig. 6 and 7 show the graph plotted between the run number and the internally studentized residuals of axial $\left(\mathrm{Y}_{4}-\mathrm{Y}_{9}\right)$ and radial swelling $\left(\mathrm{Y}_{10}-\mathrm{Y}_{15}\right)$, respectively, at the various time points. In the throughly randomized run, the vertical expansion of the internally studentized residuals was in line from bottom to top, indicating that all data points lay within the limits of a $95 \%$ confidence interval.

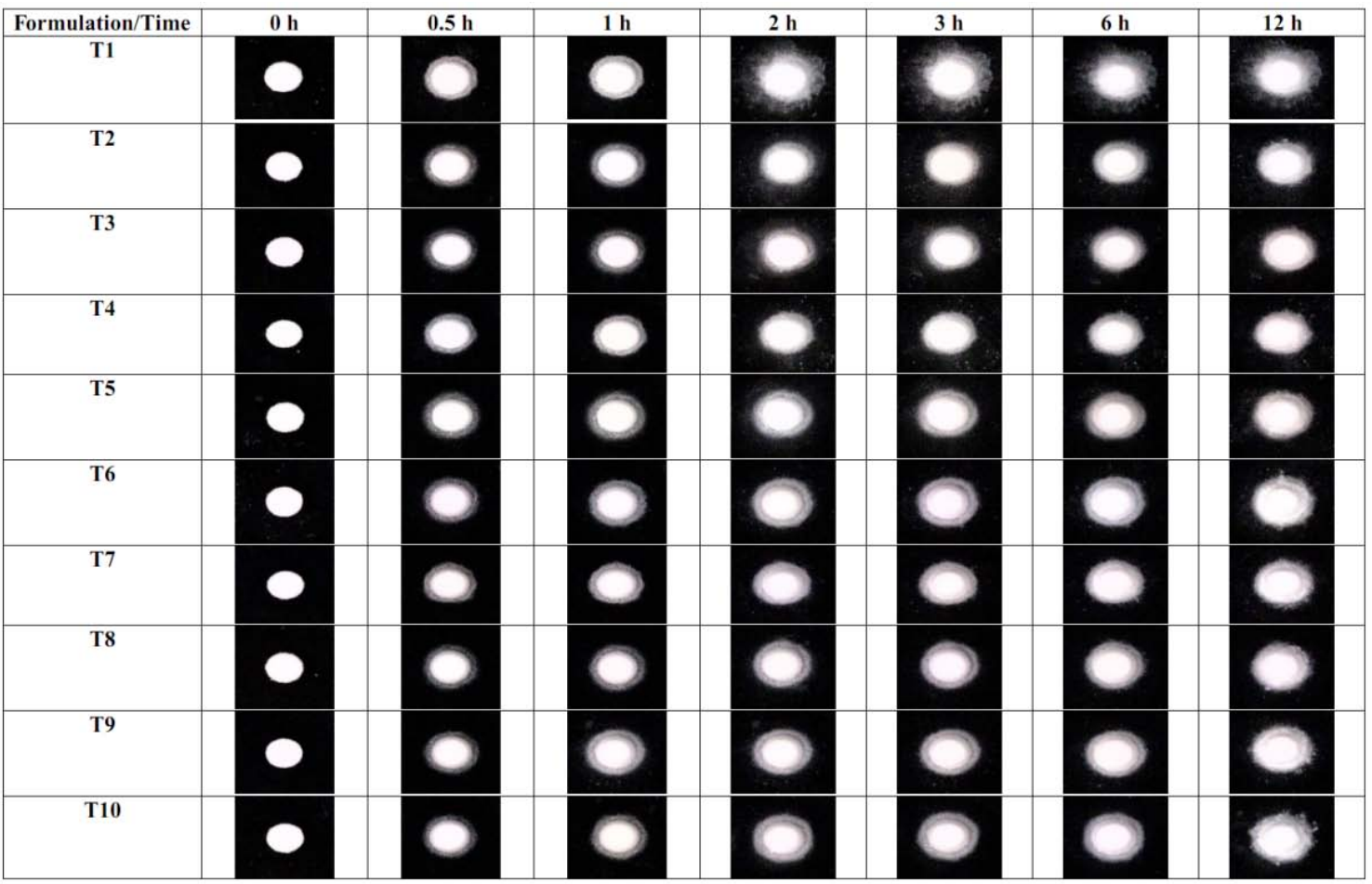

Fig. 4: Radial swelling behavior of HPMC matrix tablets at various times $\left(\mathrm{Y}_{10}-\mathrm{Y}_{15}\right)$
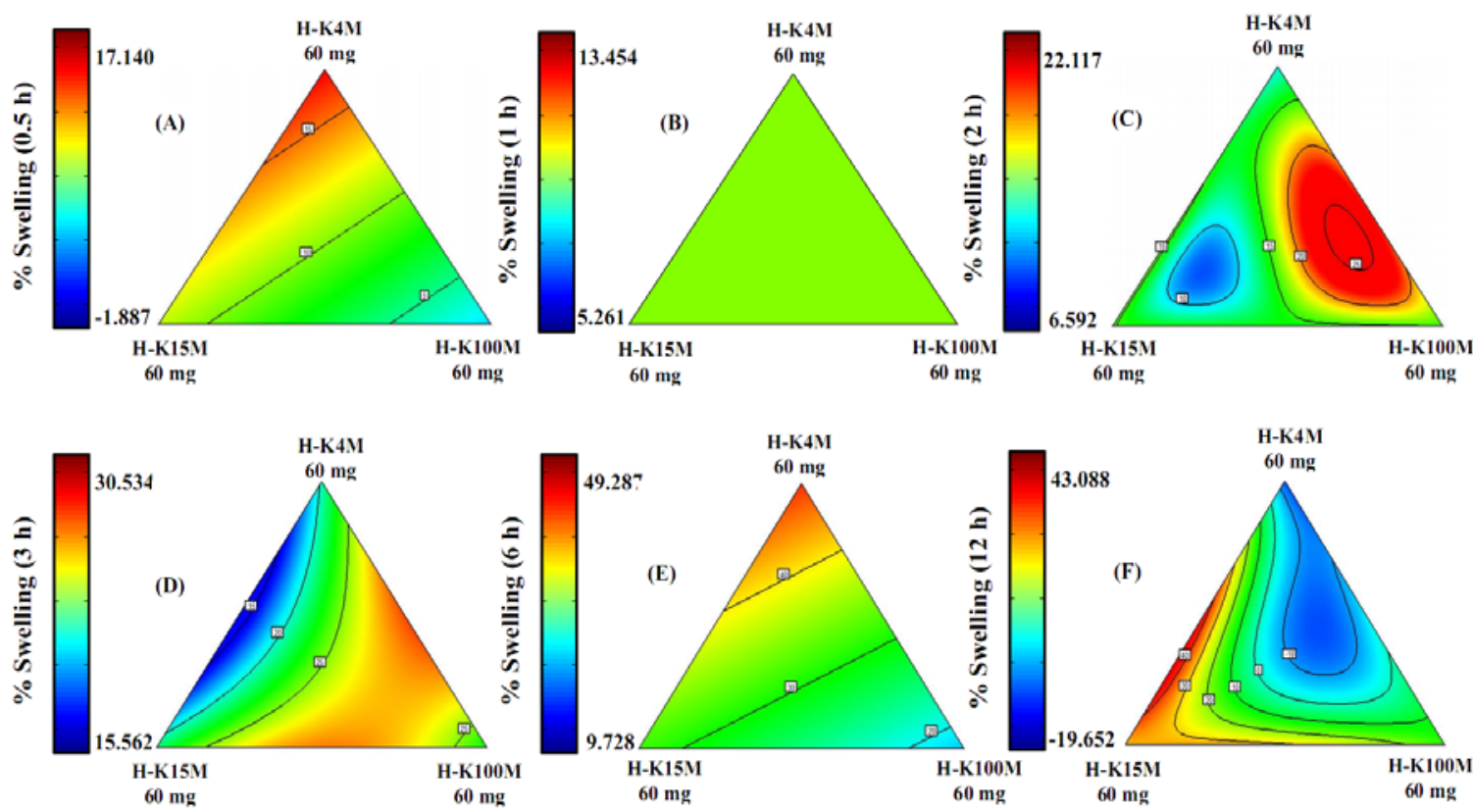

Fig. 5: Contour plots of HPMC matrix tablets for (\%) radial swelling at $0.5 \mathrm{~h}\left(\mathrm{~A}, \mathrm{Y}_{10}\right), 1 \mathrm{~h}\left(\mathrm{~B}, \mathrm{Y}_{11}\right), 2 \mathrm{~h}\left(\mathrm{C}, \mathrm{Y}_{12}\right), 3 \mathrm{~h}\left(\mathrm{D}, \mathrm{Y}_{13}\right), 6 \mathrm{~h}\left(\mathrm{E}, \mathrm{Y}_{14}\right)$ and 12 $h\left(F, Y_{15}\right)$ 

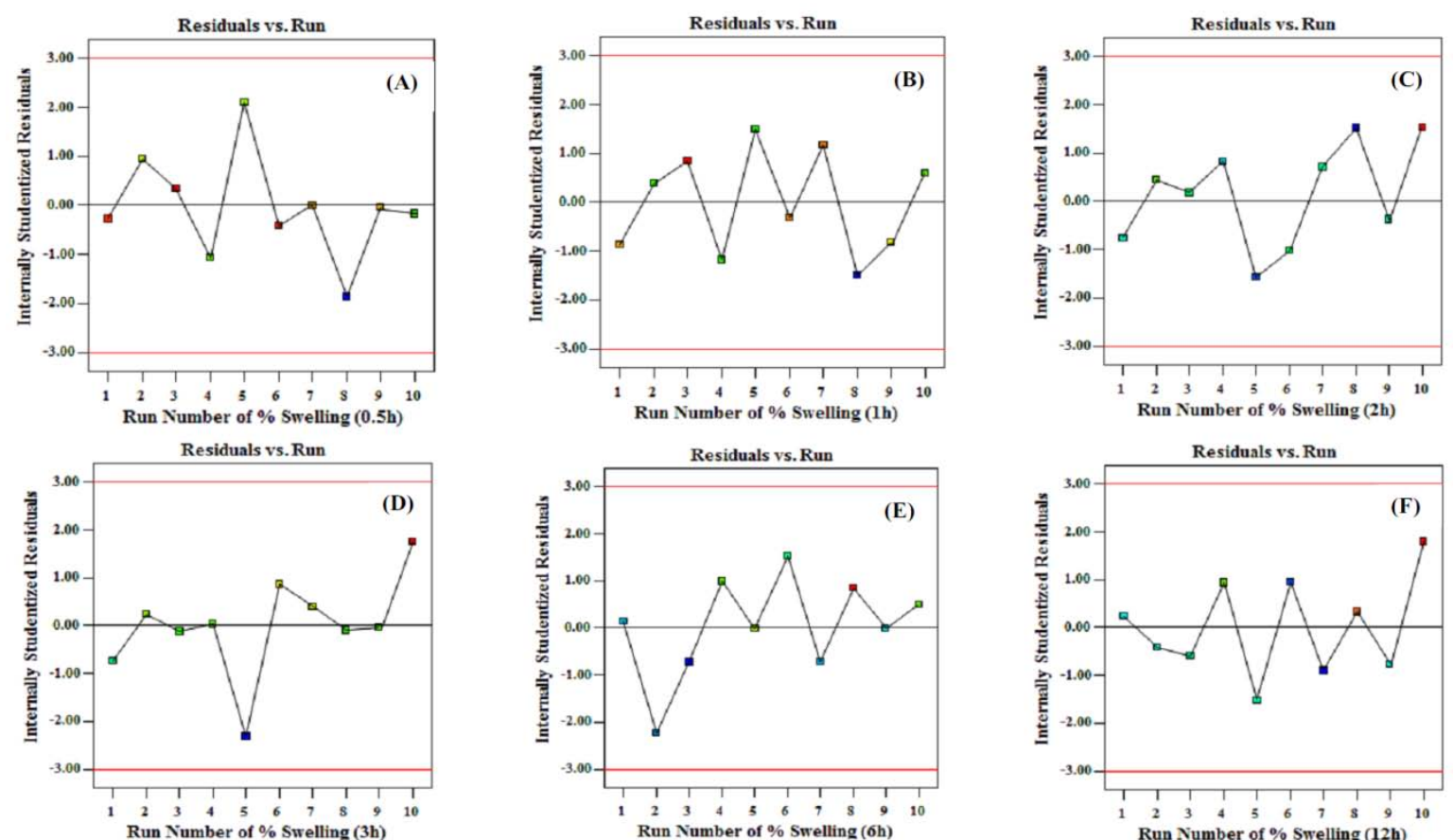

Fig. 6: The corresponding residual plot between run number and internally studentized residuals for (\%) axial swelling of HPMC matrix tablets at $0.5 \mathrm{~h}\left(\mathrm{~A}, \mathrm{Y}_{4}\right), 1 \mathrm{~h}\left(\mathrm{~B}, \mathrm{Y}_{5}\right), 2 \mathrm{~h}\left(\mathrm{C}, \mathrm{Y}_{6}\right), 3 \mathrm{~h}\left(\mathrm{D}, \mathrm{Y}_{7}\right), 6 \mathrm{~h}\left(\mathrm{E}, \mathrm{Y}_{8}\right)$ and $12 \mathrm{~h}\left(\mathrm{~F}, \mathrm{Y}_{9}\right)$
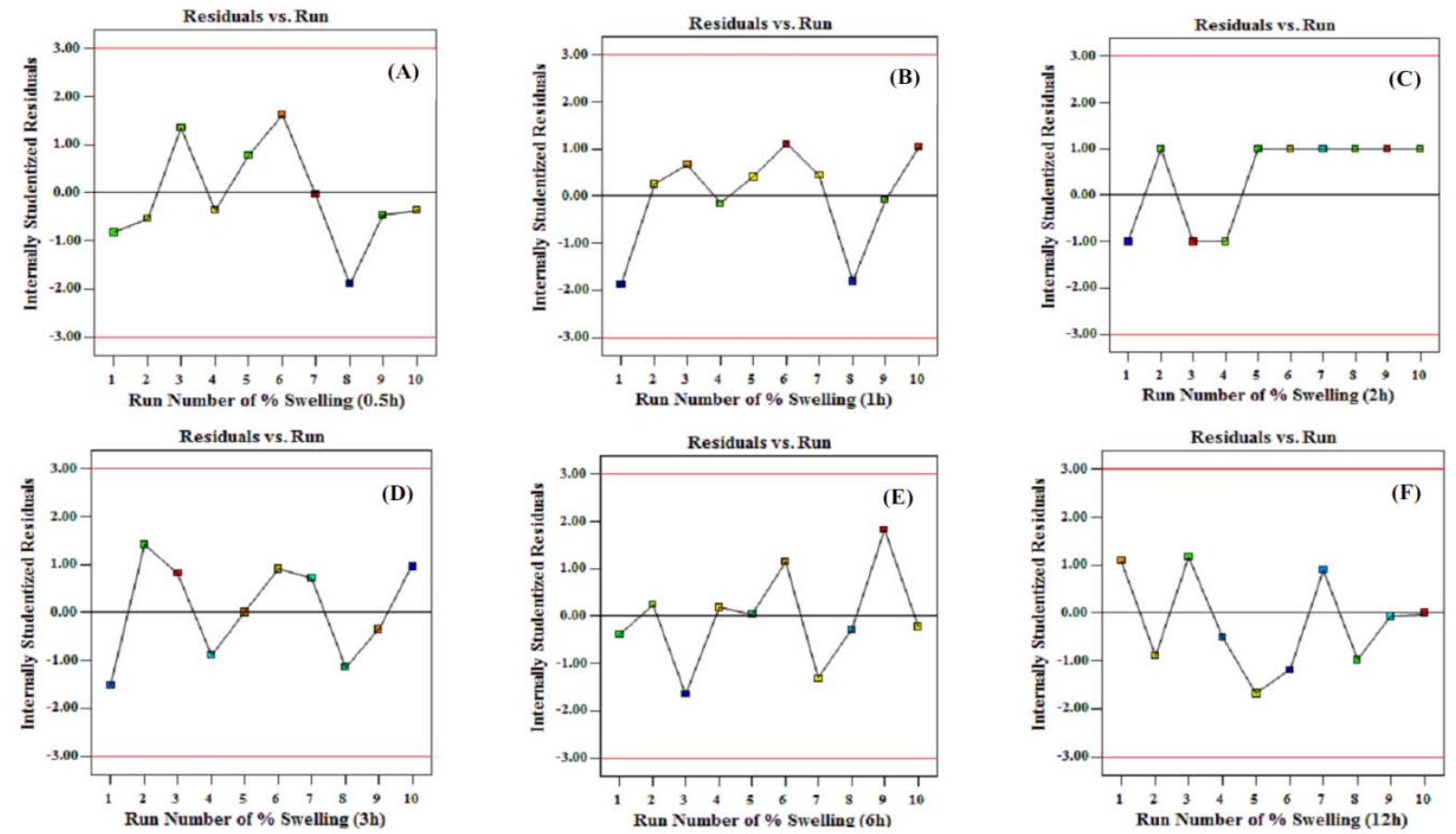

Fig. 7: The corresponding residual plot between run number and internally studentized residuals for (\%) radial swelling of HPMC matrix tablets at $0.5 \mathrm{~h}\left(\mathrm{~A}, \mathrm{Y}_{10}\right), 1 \mathrm{~h}\left(\mathrm{~B}, \mathrm{Y}_{11}\right), 2 \mathrm{~h}\left(\mathrm{C}, \mathrm{Y}_{12}\right), 3 \mathrm{~h}\left(\mathrm{D}, \mathrm{Y}_{13}\right), 6 \mathrm{~h}\left(\mathrm{E}, \mathrm{Y}_{14}\right)$ and $12 \mathrm{~h}\left(\mathrm{~F}, \mathrm{Y}_{15}\right)$

\section{In vitro release of HPMC matrix tablets and drug release kinetics}

The contour plot for the in vitro release of PNL from the tablets in buffer solution at $\mathrm{pH} 1.2(1 \mathrm{~h})$ and $\mathrm{pH} 7.5(3-12 \mathrm{~h})$ was $21.12-$ $76.22 \%$ (fig. 8). Therefore, the various HPMC molecular weights and concentrations could significantly impede the release rate of PNL from the tablet until hour 12. The PNL release patterns at different HPMC ratios and molecular weights were quite similar in the 1-6-h period. Tablets with a high proportion of $\mathrm{H}-\mathrm{K} 100 \mathrm{M}$ had greaterPNL release, shown as yellow or orange areas in the contour plot. Typically, any polymer with a higher molecular weight results in a decreased release rate due to the stronger gel barrier $[3,9]$. These authors described the swelling property of polymers, where polymers with high molecular weights led to greater matrix swelling, leading to the reduced release rate of the model drug. However, it was difficult to clarify our results with only the swelling property, as it does not only depend on the molecular weight of the HPMC but also the duration the tablets were submerged in the 
experimental media. Other reports correlate with our result and clarify that the high release of high-molecular weight polymer may be due to the faster disintegration of the tablets [22]. In addition, the different HPMC molecular weights may have little influence on drug release because soluble drugs can dissolve quickly in water or acidic and basic medium before complete swelling occurs [12]. Therefore, we may summarize that the HPMC concentration and molecular weight crucially influence the release rate of PNL from the tablets, such that extended-release tablets can be formulated by modifying the HPMC concentrations and molecular weights as appropriate. Table 2 shows the mathematical release models of the HPMC matrix tablets. The fitting models selected for the release pattern were zero-order, first-order, Higuchi, and Korsmeyer-Peppas models. In the present study, all formulations showed a good fit with the
Korsmeyer-Peppas model, as it showed a maximum correlation coefficient $\left(\mathrm{R}^{2}\right)$, indicating that the mechanism of PNL release from the tablets was diffusion-and erosion-controlled [3, 23]. The release exponent values (n) of the present study (cylindrical shape) were around 0.45, indicating classical Fickian diffusion-controlled drug release $[8,13,23]$. In addition, the axial and radial swelling study support this release mechanism, in that tablet erosion and swelling were observed for all formulations. Therefore, the release patterns of the HPMC matrix tableffit ting the Korsmeyer-Peppas model propose drug release by diffusion and erosion.

Fig. 8 shows that the suitable model was analyzed by comparing run number versus internally studentized residuals, and showed that the data points fellwithin the limits.
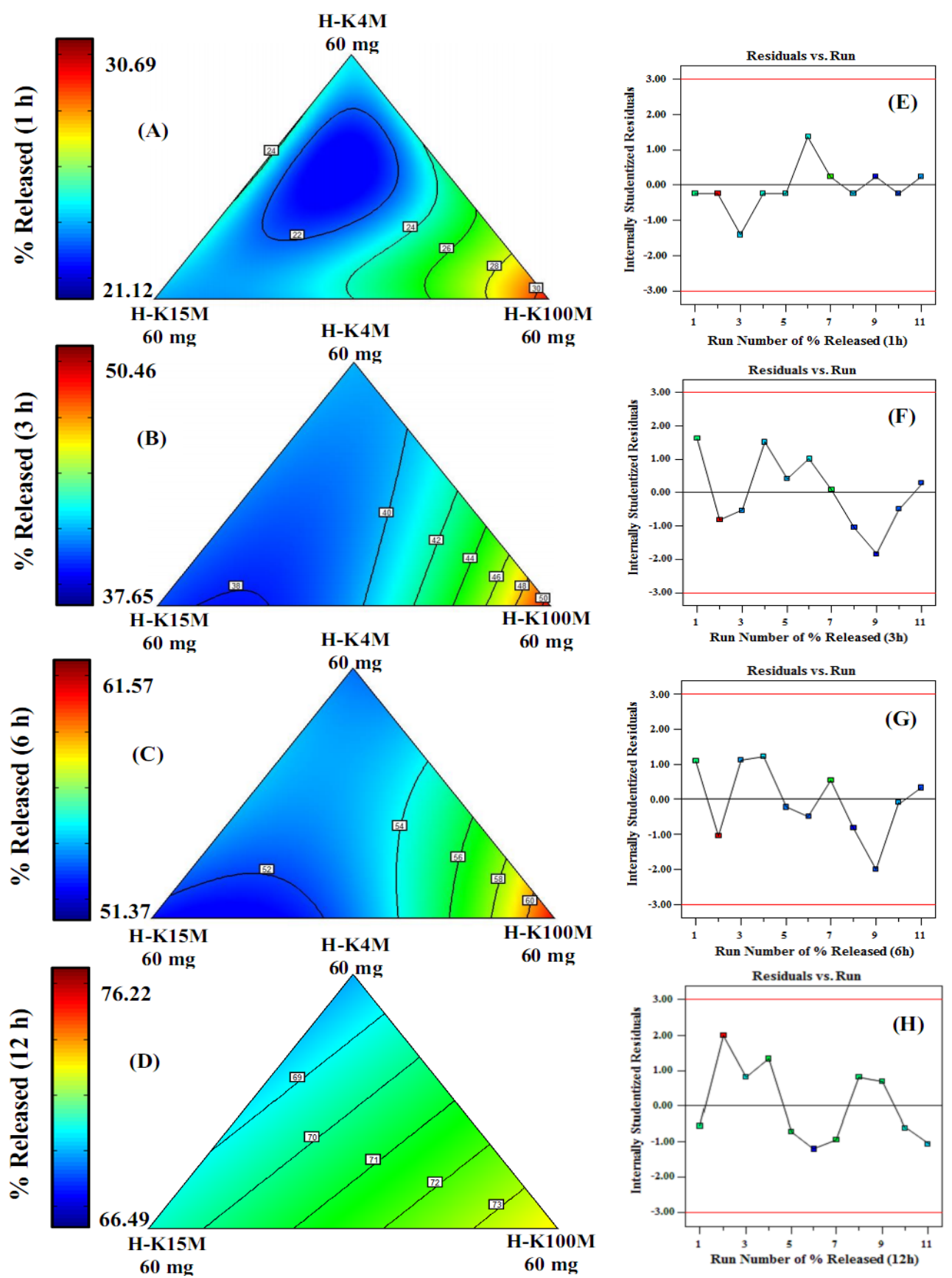

Fig. 8: Contour plots of the in vitro release of PNL from HPMC matrix tablets at $1 \mathrm{~h}\left(\mathrm{~A}, \mathrm{Y}_{16}\right), 3 \mathrm{~h}\left(\mathrm{~B}, \mathrm{Y}_{17}\right), 6 \mathrm{~h}\left(\mathrm{C}, \mathrm{Y}_{18}\right), 12 \mathrm{~h}\left(\mathrm{D}, \mathrm{Y}_{19}\right)$ and the corresponding residual plot between run number and internally studentized residuals for the in vitro release at $1 \mathrm{~h}\left(\mathrm{E}, \mathrm{Y}_{16}\right), 3 \mathrm{~h}\left(\mathrm{~F}, \mathrm{Y}_{17}\right), 6$ $h\left(G, Y_{18}\right)$ and $12 h\left(H, Y_{19}\right)$ 
Table 2: In vitro release kinetics of PNL from HPMC matrix tablets

\begin{tabular}{|c|c|c|c|c|c|}
\hline \multirow[t]{2}{*}{ Formulation } & \multicolumn{5}{|c|}{ Mathematical release models } \\
\hline & Zero order $\left(\mathbf{R}^{2}\right)$ & First order $\left(\mathbf{R}^{2}\right)$ & Higuchi $\left(\mathbf{R}^{2}\right)$ & $\begin{array}{l}\text { Korsmeyer- } \\
\text { peppas }\left(\mathrm{R}^{2}\right)\end{array}$ & Koresmeyer-peppas release exponent (n) \\
\hline $\mathrm{T} 1$ & 0.7747 & 0.9265 & 0.9652 & 0.9866 & 0.3645 \\
\hline $\mathrm{T} 2$ & 0.8590 & 0.9629 & 0.9940 & 0.9988 & 0.4341 \\
\hline T3 & 0.8762 & 0.9709 & 0.9973 & 0.9996 & 0.4529 \\
\hline $\mathrm{T} 4$ & 0.8160 & 0.9374 & 0.9820 & 0.9950 & 0.4001 \\
\hline T5 & 0.8583 & 0.9574 & 0.9939 & 0.9972 & 0.4493 \\
\hline T6 & 0.8640 & 0.9618 & 0.9945 & 0.9949 & 0.4709 \\
\hline $\mathrm{T} 7$ & 0.8241 & 0.9402 & 0.9844 & 0.9920 & 0.4190 \\
\hline T8 & 0.8546 & 0.9608 & 0.9932 & 0.9986 & 0.4338 \\
\hline T9 & 0.8830 & 0.9736 & 0.9980 & 0.9978 & 0.4859 \\
\hline $\mathrm{T} 10$ & 0.8536 & 0.9564 & 0.9928 & 0.9965 & 0.4453 \\
\hline
\end{tabular}

\section{CONCLUSION}

The simplex centroid design was used to evaluate the effect of HPMC concentration and type on the weight, thickness, hardness, $\%$ swelling, and \% release of PNL from HPMC matrix tablets. The tablets were prepared by direct compression. The HPMC concentrations did not influence the tablet weight significantly. The highest thickness was observed only for tablets containing $\mathrm{H}$ $\mathrm{K} 15 \mathrm{M}$, but was not significant. High hardness values were observed only in tablets with high $\mathrm{H}-\mathrm{K} 4 \mathrm{M}$ and $\mathrm{H}-\mathrm{K} 100 \mathrm{M}$ ratios. The different equilibrium swelling time of the tablets depended on the HPMC ratios and molecular weights. Tablets with high proportions of H-K100M had greater PNL release, and the mechanism of PNL release from the tablets was diffusion-and erosion-controlled. Therefore, the simplex centroid design is potentially advantageous for formulating HPMC matrix tablets of PNL.

\section{ACKNOWLEDGEMENT}

The author gratefully acknowledges the Faculty of Pharmacy, Thammasat University for financial support. In addition, the author would like to thank Dr. Kamonrak Cheewatanakornkool for evaluation of swelling behavior of HPMC matrix tablets and Rama Production Company for kindly giving HPMC samples. Grateful thanks also go to Faculty of Pharmacy, Silpakorn University for supporting facilities and equipment.

\section{AUTHORS CONTRIBUTIONS}

All the author have contributed equally

\section{CONFLICT OF INTERESTS}

The author declares no conflict of interest

\section{REFERENCES}

1. Duangjit S, Kraisit P. Optimization of orodispersible and conventional tablets using simplex lattice design: relationship among excipients and banana extract. Carbohydr Polym 2018;193:89-98.

2. Huang YB, Tsai YH, Yang WC, Chang JS, Wu PC, Takayama K. Once-daily propranolol extended-release tablet dosage form: formulation design and in vitro/in vivo investigation. Eur J Pharm Biopharm 2004;58:607-14.

3. Sriamornsak P, Thirawong N, Weerapol Y, Nunthanid J, Sungthongjeen S. Swelling and erosion of pectin matrix tablets and their impact on drug release behavior. Eur J Pharm Biopharm 2007;67:211-9.

4. Gil EC, Colarte AI, Bataille B, Pedraz JL, Rodriguez F, Heinamaki J. Development and optimization of a novel sustained-release dextran tablet formulation for propranolol hydrochloride. Int J Pharm 2006;317:32-9.

5. Hiremath PS, Saha RN. Controlled release hydrophilic matrix tablet formulations of isoniazid: design and in vitro studies. AAPS PharmSciTech 2008;9:1171-8.

6. Bose A, Wong TW, Singh N. Formulation development and optimization of sustained release matrix tablet of Itopride $\mathrm{HCl}$ by response surface methodology and its evaluation of release kinetics. Saudi Pharm J 2013;21:201-13.
7. Huanbutta K, Cheewatanakornkool K, Terada K, Nunthanid J, Sriamornsak P. Impact of salt form and molecular weight of chitosan on swelling and drug release from chitosan matrix tablets. Carbohydr Polym 2013;97:26-33.

8. Siepmann J, Peppas NA. Modeling of drug release from delivery systems based on hydroxypropyl methylcellulose (HPMC). Adv Drug Delivery Rev 2001;48:139-57.

9. Viriden A, Wittgren B, Larsson A. Investigation of critical polymer properties for polymer release and swelling of HPMC matrix tablets. Eur J Pharm Sci 2009;36:297-309.

10. Kraisit $P$, Limmatvapirat $S$, Luangtana-Anan M, Sriamornsak $P$. Buccal administration of mucoadhesive blend films saturated with propranolol loaded nanoparticles. Asian J Pharm Sci 2018;13:34-43.

11. Mohamed FAA, Roberts M, Seton L, Ford JL, Levina M, Rajabi Siahboomi AR. The influence of HPMC concentration on release of theophylline or hydrocortisone from extended release minitablets. Drug Dev Ind Pharm 2013;39:1167-74.

12. Mohamed FAA, Roberts M, Seton L, Ford JL, Levina M, RajabiSiahboomi AR. Production of extended release mini-tablets using directly compressible grades of HPMC. Drug Dev Ind Pharm 2013;39:1690-7.

13. Phaechamud T, Darunkaisorn W. Drug release behavior of polymeric matrix filled in capsule. Saudi Pharm J 2016;24:627-34.

14. Kraisit P, Limmatvapirat S, Nunthanid J, Sriamornsak P, Luangtana Anan M. Preparation and characterization of hydroxypropyl methylcellulose/polycarbophil mucoadhesive blend films using a mixture design approach. Chem Pharm Bull 2017;65:284-94.

15. Sood S, Jain K, Gowthamarajan K. Optimization of curcumin nanoemulsion for intranasal delivery using design of experiment and its toxicity assessment. Colloids Surf B 2014;113:330-7.

16. Kraisit P, Sarisuta N. Development of triamcinolone acetonideloaded nanostructured lipid carriers (NLCs) for buccal drug delivery using the box-behnken design. Molecules 2018;23:E982.

17. Nunthanid J, Luangtana Anan M, Sriamornsak P, Limmatvapirat S, Huanbutta K, Puttipipatkhachorn S. Use of spray-dried chitosan acetate and ethylcellulose as compression coats for colonic drug delivery: effect of swelling on triggering in vitro drug release. Eur J Pharm Biopharm 2009;71:356-61.

18. Oh CM, Heng PWS, Chan LW. A study on the impact of hydroxypropyl methylcellulose on the viscosity of PEG melt suspensions using surface plots and principal component analysis. AAPS PharmSciTech 2015;16:466-77.

19. Chomto P, Nunthanid J. Physicochemical and powder characteristics of various citrus pectins and their application for oral pharmaceutical tablets. Carbohydr Polym 2017;174:25-31.

20. Sauri J, Millan D, Sune Negre JM, Colom H, Tico JR, Minarro M, Perez Lozano $\mathrm{P}$, et al. Quality by design approach to understand the physicochemical phenomena involved in controlled release of captopril SR matrix tablets. Int J Pharm 2014;477:431-41.

21. Kraisit P, Luangtana Anan M, Sarisuta N. Effect of various types of hydroxypropyl methylcellulose (HPMC) films on surface free energy and contact angle. Adv Mater Res 2015;1060:107-10. 
22. Huanbutta $K$, Sriamornsak $P$, Limmatvapirat $S$, Luangtana Anan $\mathrm{M}$, Yoshihashi Y, Yonemochi E, et al. Swelling kinetics of spraydried chitosan acetate assessed by magnetic resonance imaging and their relation to drug release kinetics of chitosan matrix tablets. Eur J Pharm Biopharm 2011;77:320-6.
23. Limmatvapirat S, Limmatvapirat C, Puttipipatkhachorn S, Nunthanid J, Luangtana Anan M, Sriamornsak P. Modulation of drug release kinetics of shellac-based matrix tablets by in-situ polymerization through annealing process. Eur J Pharm Biopharm 2008;69:1004-13. 